International Journal for the Semiotics of Law Vol.VIII no.23 [1995]

\title{
LEGAL SIGNS AND LEGAL SCIENCE
}

The Relevance of Pragmaticism for the Institutional Theory of Law*

by

WOUTER G. W ERNER

University of Twente

\section{Introduction}

In 1985 Ota Weinberger and Neil MacCormick presented their socalled "institutional theory of law"(ITL). 1 The institutional theory of law is a new and interesting attempt to solve some long-standing problems concerning the nature and existence of law. It is based on insights borrowed from functionalism and from John Searle's philosophy of language (speech act theory). One of the problems considered in ITL is the relation between the validity and the efficacy of legal norms: the fact that law is a system of norms which are not reducible to facts whereas, at the same time, legal norms must be efficacious in order to retain their validity. ITL aims at giving an explanation of the nature and existence of legal norms, while avoiding the mistakes of both material approaches (reducing law to fact) and idealist approaches (completely separating law from fact):

What we aim to do in proposing our Institutional Theory of Law is to explain and account for the existence of norms and legal institutions and other similar thought-objects which on the one hand avoids the traps of idealism to which realists and materialists have always rightly objected but which on the other hand avoids the pitfalls of reductionism to which realist theories have always tended. ${ }^{2}$

* I thank Dick W. P. Ruirer for comments on earlier drafts. On the term "Pragmaticism", see n.19, below.

1 N. MacCormick \& O. Weinberger, Grundlagen des institutionalistichen Rechtspositivismus, (Berlin: Duncker \& Humblot, 1985). Quotations are from the English translation: N. MacCormick \& O. Weinberger, An Institutional Theory of Law (Dordrecht: D. Reidel Publishing Company, 1986).

2 Supra n.1, at 6. 
This article has two aims:

(1) to explain why ITL, notwithstanding its fruitful contributions to jurisprudence, cannot satisfactorily account for the character of legal norms and institutions;

(2) to sketch the general outline of a pragmatistic theory of language which may prove useful in solving some of the problems considered in ITL.

In the section 2 , the importance of the problem of validity and efficacy for analytic jurisprudence is demonstrated. On the basis of a short exposition of Kelsen's pure theory of law, it will become clear that the relation between validity and efficacy is a serious problem for every legal theory based on a conception of law as separated from morality as well as the factual domain.

The solution provided by ITL to the problem of validity and efficacy is discussed in the third section. Within ITL, the dual character of law is stated in terms of "normative" and "real" institutions. The reality of normative institutions is explained by means of a theory of human action. Although this hermeneutic, action-oriented approach is promising, ITL fails to meet its own requirements because it cannot explain the reality of normative institutions.

In the fourth section, some outlines of the pragmatistic theory of language are sketched. As early as 1902, Charles Sanders Peirce developed some basic notions of speech act theory. As will be explained, this theory is important to ITL because it emphasizes the relation between the meaning of a speech act and its conceivable (social) consequences.

\section{Kelsen's Legacy: Law as Norm and Law as Fact}

Some years ago, Stanley L. Paulson distinguished four possible theses concerning the nature of law: ${ }^{3}$

1a. The morality thesis, expressing the idea that positive law cannot be separated from morality;

1b. The separability thesis, claiming the separability of law and morality. The clearest expression of the separability thesis is

3 S.L. Paulson, "Kelsen's Legal Theory: The Final Round", Oxford Journal of Legal Studies 12/2 (1992), 265-274. 
John Austin's adage: "the existence of law is one thing; its merit or demerit is another." 4

2a The reductive thesis, stating that law and fact cannot be separated: ultimately, law is explained in factual terms;

2b. The normativity thesis, claiming that law and fact are to be separated.

Kelsen's pure theory of law is based on both the separability thesis and the normativity thesis. The existence of law can be accounted for neither in moral terms nor in factual terms. The separation of law and morality indicates that Kelsen is not concerned with the ethical question what ought to be law, but with an explanation of law as it actually is. The separation of law and fact, furthermore, makes it clear that Kelsen conceives of positive law as a normative phenomenon, as an order of norms.

The separation of law and fact is based on a more fundamental distinction between the categories Is and Ought. According to Kelsen, these two categories are basic determinations of the human mind (Denkbestimmungen), that escape further reflection. Owing to their fundamental status, the categories $I s$ and Ought are separated by a logical gap. It is neither possible to infer from the existence of a state of affairs the validity of a norm nor to infer the existence of a state of affairs from the existence (validity) of a norm:

Ought is a "basic category" just like Is; and we can no more give a definition of Ought than we can describe what Being is.

An Ought cannot be reduced to an Is, or an Is to an Ought; and so Is cannot be inferred from Ought, or an Ought from an Is. ${ }^{5}$

Although Kelsen has always objected to attempts to reduce law to fact, he is nevertheless forced to recognize a fundamental problem connected with the normativity thesis. Conceptually speaking, it is not absurd to conceive of legal rules belonging neither to critical nor to positive morality. However, a strict separation between the existence of legal

4 J. Austin, The Province of Jurisprudence Determined and The Uses of the Study of Jurisprudence (London: Weidenfeld \& Nicolson, 1965), 184.

5 H. Kelsen, General Theory of Norms (Oxford: Clarendon Press, 1991), 2, 58, translation by Michael Hartney of Allgemeine Theorie der Normen (Wien: Manz, 1979). 
norms and their effectiveness is, according to Kelsen, conceptually impossible. Positive law does not consist of mere "thought-norms", but is composed of norms that are actually operative in the legal community. In order to account for the factual aspect of law, Kelsen qualifies the efficacy of legal norms as a condition for their continuing existence:

The effectiveness of a legal order as a whole and the effectiveness of a single legal norm are $[. .$.$] the condition for the validity; effectiveness is the$ condition in the sense that a legal order as a whole, and a single legal norm can no longer be regarded as valid when they cease to be effective. ${ }^{6}$

However, by introducing the efficacy of legal norms as a necessary condition for their continual existence, Kelsen abandons his own strict position with respect to the separation of norm and fact (Is and Ought). $\mathrm{He}$ is forced to recognize that within the pure theory of law it is impossible to account for the fact that "the law appears as "ought" and as "is" at the same time, while logically these two categories are mutually exclusive." 7

\section{The Institutional Theory of Law}

ITL accepts the basic tenets of legal positivism: valid law can be derived neither from morality nor from mere fact. Moreover, it seeks to analyze positive law on the basis of the so called "speech act theory" developed by J.L. Austin and John Searle. In the first sub-section, we shall investigate how the adoption of speech act theory determines the way in which the problem of validity and efficacy is stated by ITL. In the second sub-section, Weinberger's attempt to solve the problem of the relation between validity and efficacy will be discussed.

\subsection{The Concept of a Legal Institution}

Within ITL, the legal order is conceived of as a system that includes two types of rule: regulative and constitutive rules. Regulative rules, in the words of John Searle, "regulate a pre-existing activity, whose

6 H. Kelsen, Pure Theory of Law (Berkeley: University of California Press 1967), 211, 212, translation of: Reine Rechtslehre (Wien: F. Deuticke, 1960).

7 H. Kelsen, General Theory of Law and State (New York, Russell \& Russell, 1946), 393-394. 
existence is logically independent of the rules." 8 Examples of regulative rules are the prohibition of murder or the command to love one's enemies. Constitutive rules are of a different type. Constitutive rules "constitute an activity the existence of which is logically dependent on the rules." "Examples of constitutive rules are scoring rules in a game or the rules by which a chairman is appointed. Scoring or appointing are activities that can exist only in virtue of rules stating that a certain type of behaviour counts as scoring a goal or appointing a chairman. The characteristic formulation of a constitutive rule is " $\mathrm{X}$ counts as $\mathrm{Y}$ in context C", 10

In addition to new forms of behaviour, constitutive rules also make possible the creation of new facts: facts such as a checkmate, a marriage between Charles and Diana or the election of a new president. The facts referred to cannot be known by empirical observation alone. In order to account for these kind of facts, one must have knowledge of the constitutive rules underlying them. Such rule-governed facts Searle calls institutional facts. All institutional facts exist in virtue of an underlying institution, consisting of constitutive rules.

Searle's analysis of institutions and institutional facts is applied to law by Neil MacCormick. " MacCormick distinguishes between the institution itself (the legal concept such as "contract") and instances of an institution (legal facts such as the contract between North and Jones).

The institution itself consists of three types of rules: ${ }^{12}$

a. Institutive rules laying down under what circumstances an instance of an institution comes into existence. Institutive rules take the form of constitutive rules: certain forms of behaviour count as contracting, marrying, divorcing, etc.

8 J.R. Searle, Speech Acts (Cambridge: Cambridge University Press, 1969), 34.

9 Supra n.8, at 34.

10 Supra n.8, at 35.

11 In 1993, Dick W.P. Ruiter also applied Searle's theory of speech acts to legal theory. In his Institutional Legal Facts (Dordrecht: Kluwer Academic Publishers, 1993). Ruiter develops a classification of seven possible acts-in-thelaw: declarative, hortatory, imperative, purposive, commisive, assertive and expressive. Moreover, Ruiter seeks to analyze negative acts-in-the-law and develops a logic of acts-in-the-law.

12 Supra n.1, at $53,54$. 
b. Consequential rules stating the rights, duties and legal powers following from the existence of an instance of an institution.

c. Terminative rules providing for the termination of an instance of an institution.

Law can be conceived of as a system of institutions, that makes the creation of institutional legal facts possible. However, MacCormick recognizes that his analysis of law as a system of institutions may be misunderstood as being based on the "belief in a formalistic heaven of institutions, each with its neatly packaged set of essential rules which nicely settle all questions" ${ }^{13}$ It goes without saying that this is not what is meant by MacCormick's analysis of legal institutions. According to ITL, law is both a system of rules and a social phenomenon, a system of action. Therefore, legal facts exist in a dual way:

1. As institutional facts, in virtue of constitutive legal rules;

2. As social realities, developed and applied in the praxis of the legal community.

In conclusion, we may state that Kelsen's duality of $I s$ and Ought is translated by ITL into a duality of law as an system of institutions and as a social reality at the same time.

\subsection{Normative and Real Institutions}

Weinberger distinguishes between normative institutions and real institutions. Normative institutions are systems of rules as mentioned above, making possible the creation of institutional legal facts. Such institutional facts, Weinberger says, can be considered as thoughts in an objective sense. ${ }^{14}$ They exist apart from our individual consciousness and apart from the social consequences they have in the legal community. Institutional facts (norms) exist in virtue of the rules of an institution which also determine their meaning. Real institutions, on the other hand, are systems of actual behaviour, consisting in regularities in conduct and the expectations based thereupon. The reality of institutions and institutional legal facts appears in the consciousness of human actors, in the motivational function of institutions and in the

13 Supra n.1, at 67. See also Ruiter, supra n.11, at 97-102.

14 Supra n.1, at 33. 
social consequences following from the existence of institutional facts. ${ }^{15}$

Weinberger seeks to integrate both types of institution by means of a theory of human action. Action is defined as behaviour determined by a processing of information:

Handlung ist informationsbestimmtes intentionales Verhalten eines gewissen Subjektes. ${ }^{16}$

Information can be of two kinds: theoretical and practical. Theoretical information consists of sentences describing facts and causal relationships between facts. The pragmatic function of theoretical information is to provide an actor with knowledge about things being the case. Theoretical information enables an actor to adjust his behaviour to the environment. Practical information consists of goals, principles, norms, etc. The pragmatic function of practical information is to enable an actor to choose between possible courses of action and eventually to adjust the world to his norms and preferences. Weinberger defines institutions as a kind of practical information covering both their real and their normative aspects:

Institutions are frame-work systems of human action. They have a core of practical informations. In the sense that they consist of an ordered system of practical informations which is effective in conjunction with psychological and social facts and events they are always complex objects. ${ }^{17}$

At first sight, it seems that Weinberger has solved the tension between validity and efficacy of law: legal institutions (and institutional facts) are a kind of practical information. Therefore, they are both a thought in the objective sense and a social reality. On further reflection, however, it appears that the relationship between normative institutions and real institutions is not a conceptual, but only a functional one. Institutional facts exist as meaningful thought-objects detached from processes of consciousness and from social practices. They become social realities because they are used as instruments by human actors. Their meaning, however, is constituted by the rules of the institution in virtue of which they exist. According to Weinberger, practical data are

15 Supra n.1, at 41.

16 O. Weinberger, Norm und Institution. Eine Einfürung in die Rechtstheorie (Wien: Manz, 1988), 18.

17 O. Weinberger, Law, Institution and Legal Politics (Dordrecht: Kluwer Academic Publishers, 1991), 21. 
"possible objects of thought" becoming real only through actual use by goal-oriented actors. ${ }^{18}$ Consequently, normative institutions as meaningful thoughts in the objective sense are conceptually distinguished from real institutions as social practices.

In order to be able to solve the problems attached to the dual nature of institutions, it is therefore necessary to reveal the conceptual relation between the meaning and the social consequences of institutions and speech acts.

\section{Pragmaticism}

In this section, we shall try to sketch some general outlines of a theory of language in which the relation between the meaning and the consequences of speech acts is revealed. This theory can be useful to ITL and help to get a better understanding of the problem of validity and efficacy. The theory under discussion is developed by C.S. Peirce, the originator of the pragmatic movement, and G.H. Mead, who applied the insights of the pragmatic movement to social psychology. Both Peirce and Mead can be considered as pragmaticists: they reject the nominalistic and subjectivistic interpretations of the pragmatic doctrine and emphasize the reality of "generals" (types and laws) and the importance of intersubjectivity in matters of truth and justice. ${ }^{19}$

Traditionally, pragmaticism is not associated with legal positivism. According to Max Fisch, the pragmatic movement can even be considered as a generalization of the prediction theory of law, a theory which has always been severely criticized by legal positivists. ${ }^{20} \mathrm{Never-}$ theless, there is also an important element shared by pragmaticism and legal positivism. Both pragmaticism and legal positivism aim at a clarifi cation of concepts and a purification of scientific language from

Supra n.1, at 16

19 In 1905, Peirce renamed his doctrine Pragmaticism, a name, according to Peirce, "ugly enough to be save from kidnappers": C.S. Peirce, Collected Papers, (Cambridge: Harvard University Press, 1958), 5.414.

20 M. Fisch, Peirce, Semeiotic and Pragmatism (Bloomington: Indiana University Press, 1986), 12, states that: "we may safely infer either that the prediction theory of law was developed by applying that doctrine [of pragmatism - WW] to the special case of law, or, as I think more likely, that pragmatism was a generalization of the prediction theory of law." 
meaningless propositions and concepts. Just as legal positivism tries "to pluck the mask of Mystery from the face of Jurisprudence", pragmati cism tries to do away with concepts not open to rational proof:

The elements of every concept enter into logical thought at the gate of perception and make their exit at the gate of purposive action; and whatever cannot show its passports at both these two gates is to be arrested as unauthorized by reason. ${ }^{21}$

A second element shared by pragmaticism and at least the institutional variant of legal positivism is the interest they take in the phenomenon of language. It is interesting to notice that in 1902, long before J.L. Austin and J. Searle came to recognize that speaking a language is a form of rule-governed behaviour, Peirce already introduced some basic notions of speech act theory. ${ }^{22}$ Peirce distinguishes between a proposition on the one hand and the use made of that proposition on the other. One and the same proposition can be used in different actions: in asserting, in questioning, in commanding etc.:

One and the same proposition may be affirmed, denied, judged, doubted, inwardly inquired into, put as a question [...] or merely expressed and does not thereby become a different proposition. ${ }^{23}$

Although Peirce shares with Searle and ITL the notion of speaking a language as a form of rule governed behaviour, there is also an important difference between pragmaticism and speech act theory. In Searle's speech act theory, the meaning of an utterance (propositional content and illocutionary force) is separated from the effects of that utterance (perlocution). Peirce, on the other hand, emphasizes the intrinsical relation between the meaning of an utterance and the conceivable consequences resulting from it. This relation can be illustrated by his famous pragmatic maxim:

Consider what effects, which might conceivably have practical bearings, we conceive the object of our conception to have. Then, our conception of

\section{Supra n.19, at 5.212.}

22 See also J.E. Brock, "Peirce and Searle on Assertion" and E. Martens, "C.S. Peirce on Speech Acts", in K.L. Ketner et al., eds, Proceedings of the C.S. Peirce Bicentennial International Congress (Lubbock: Texas Tech University, 1981), 281-289 and 289-293.

23 C.S. Peirce, The New Elements of Mathematics (The Hague: Mouton, 1976), 248. 
these effects is the whole of our conception of the object. ${ }^{24}$

It should be noticed that the consequences Peirce refers to are not merely sets of actual stimulus/response reactions. They are general, conceivable consequences that would result if man carried out (or failed to carry out) some future course of action. Moreover, some important consequences of uttering a speech act occur because certain rules exist, governing social interaction. Under these rules, a speaker is held responsible for the truth, sincerity or legitimacy of his speech act. ${ }^{25}$ In case he is unable to back up his speech acts with arguments, the speaker must take the consequences and suffer the penalties of the social law:

An act of assertion supposes that, a proposition being formulated, a person performs an act which renders him liable to the penalties of social law [...] in case it should not be true, unless he has a definite and sufficient excuse. ${ }^{26}$

The existence of social rules makes it both possible and necessary for speakers to look at their utterances from a special point of view: they must interpret their own vocal gestures as (they expect that) the other participants in the social act would do. Through this "role-taking" (Mead), their vocal gestures become part of their own environment. When speakers and hearers reach a reciprocity in their expectations concerning the interpretation of the vocal gesture, this gesture has become, as Mead calls it, a "significant symbol":

The vocal gesture becomes a significant symbol [...] when it has the same effect on the individual making it that it has on the individual to whom it is addressed or who explicitly responds to it. ${ }^{27}$

Within pragmaticism, as there is an intrinsic relation between the meaning of an utterance and its conceivable consequences, the importance of the context in which speech acts are performed becomes a matter of course. Different contexts give rise to different interpretations,

24 Supra n.19, at 5.402.

25 It may be added that the speech act has consequences also for the hearer. In the first place, the speech act provides him with theoretical, practical and expressive information, which he can use instrumentally. In the second place, the hearer can be held responsible for the way he deals with the information provided by the hearer.

26 Supra n.19, at 2.315.

27 G.H. Mead, Mind, Self and Society (Chicago: University of Chicago Press, 1962), 46 . 
expectations and conceivable consequences.

One of the contexts in which utterances are interpreted is the con text of positive law. As MacCormick and Weinberger (amongst others) have pointed out, the legal system can be considered as an extra-linguistic institution: as a system of rules indicating which utterances count as the creation of new elements of the legal system. However, as was explained above, the rules of the institution cannot completely determine the meaning of these new elements. Their meaning is not fixed in the past (the act of creation), but points to the future: it consists in the conceivable consequences that would follow from their existence. This explains why a duality of legal institutions as thought-objects on the one hand and as systems of action on the other is untenable. Existing legal institutions can be considered as signs (thought-objects) whose meaning consists in the conceivable consequences that would result if man carried out (or failed to carry out) some future course of action.

In section three we concluded that, in order to be able to solve the problem of validity and efficacy as expressed by ITL, it is necessary to reveal the relation between the meaning and the consequences of (the performance of) a speech act. In this section we tried to explain that pragmaticism offers a theory of language in which this relation is revealed. On the basis of this theory, it can be explained why a dualistic interpretation of the existence of legal institutions is untenable. This does not mean that ITL should be completely rejected and needs to be replaced by a pragmaticistic theory of law. Neither does it mean that all the questions concerning the relation between validity and efficacy can be answered by pragmaticism. ${ }^{28}$ It does indicate, however, that the insights put forward by pragmaticism can be useful for anyone who, like MacCormick and Weinberger, wants to "explain and account for the existence of norms and legal institutions [...] avoiding the traps of idealism [and] avoiding the pitfalls of reductionism." 29

\section{Summary}

The first section of this article defined two aims:

28 For example: To what extent must legal rules be effective in order to remain valid? Is it possible for norms prescribing impossible behaviour to be valid? Who must regard the legal norm as a standard for justified criticism?

Supra n.1, at 6 (quoted at p.207, above). 
(1) to explain why ITL, notwithstanding its fruitful contributions to jurisprudence, cannot satisfactorily account for the character of legal norms and institutions;

(2) to sketch the general outline of a pragmatistic theory of language which may prove useful in solving some of the problems considered in ITL.

In the second section, Kelsen's pure theory law was discussed. According to Kelsen, law and fact ought to be separated: it is impossible to infer from the existence of a state of affairs the validity of a norm or to infer the existence of a state of affairs from the validity of a norm. On the other hand, however, Kelsen states that the efficacy of legal norms (a fact) is a condition for their continuing existence.

In the third section, some elements of ITL were considered. In ITL, Kelsen's duality of law and fact is translated into a duality of normative and real institutions. Law is considered to be a system of "objective thoughts" and a system of action at the same time. Although ITL tries to integrate both types of institution, it remains unclear how law can be an objective thought (separated from social practices) and a system of action (consisting in social practices) at the same time. In order to solve the problems attached to the dual nature of institutions, it becomes necessary to reveal the conceptual relation between the meaning and the social effects of institutions and speech acts.

In the fourth section, some outlines of a pragmaticistic theory of language were sketched. In pragmaticism, there is a relation between the meaning and the conceivable consequences of (the performance of) speech acts. On the basis of this theory, existing legal institutions can be considered as signs (thought-objects) whose meaning consists in the conceivable consequences that would result if man carried out (or failed to carry out) some future course of action. 